\title{
Acute megakaryoblastic leukemia
}

INSERM

\section{Source}

INSERM. (1999). Orphanet: an online rare disease and orphan drug data base. Acute megakaryoblastic leukemia. ORPHA:518

Acute megakaryoblastic leukemia (AMKL) is a form of acute myeloid leukemia ( $A M L$; see this term) that occurs predominantly in childhood and particularly in children with Down syndrome (DS-AMKL). Nonspecific symptoms may be irritability, weakness, and dizziness while specific symptoms include pallor, fever, mucocutaneous bleeding, hepatosplenomegaly, neurological manifestations and rarely lymphadenopathy. Acute panmyelosis with myelofibrosis (see this term)may also be associated with AMKL. In contrast to DS-AMKL (around $80 \%$ survival), non-DS-AMKL is an AML subgroup associated with poor prognosis. 